\title{
On the nature and role of Consciousness: \\ is it time to move towards a metaphilosophical and metascientific approach?
}

\author{
Enrico Facco $^{1,2,3}$, Fabio Fracas ${ }^{3,4}$, Silvano Tagliagambe ${ }^{5}$, and Patrizio Tressoldi ${ }^{3,6 * 1}$ \\ ${ }^{1}$ Studium Patavinum - Dept. of Neurosciences, University of Padua, Italy \\ ${ }^{2}$ Inst. Franco Granone - Italian Center of Clinical \& Experimental Hypnosis, Turin, Italy \\ ${ }^{3}$ Science of Consciousness Research Group - Dept. of General Psychology, University of Padua, \\ Italy \\ ${ }^{4}$ Scientific Associate at CERN, Geneva, Switzerland \\ ${ }^{5}$ Professor emeritus of Philosophy of Sciences, University of Sassari, Italy. \\ ${ }^{6}$ Dept. of General Psychology, University of Padua, Italy
}

\section{Preprint version 08/01/2021}

\begin{abstract}
The main aim of this paper is to support a metaphilosophical and metascientific approach to the study of Consciousness.

After a brief historical resume of the debate between the mind-brain-body relationship, we discuss how the apparently irreducible contention between a physicalist and an anti-physicalist interpretation of Consciousness can be overcome by a metaphilosophic and metascientific approach in the attempt to overcome ethnocentric cultural filters and constraints yielded by the Weltanschauung and the Zeitgeist one belongs to. IN fact, a metaphilosophical perspective can help to recognize key concepts and meanings common to different philosophies beyond their formal differences and different modes of theorization, where the common field of reflection is aimed to find the problem's unity in the multiplicity of forms. Likewise, the metascientific approach, such as the anthropic principle adopted in astrophysics, helps overcoming the problems of indecidability of single axiomatic disciplines.
\end{abstract}

A metaphilosophical and metascientific approach seems appropriate in the study of consciousness and subjective phenomena, since the first-person perspective and the meaning of the experience are the condition sine qua non for their proper understanding.

Keywords: consciousness; epistemology; ontology; physicalism; dualism, metaphilosophy, metascience

\footnotetext{
${ }^{1}$ Corresponding author: Patrizio Tressoldi; email: patrizio.tressoldi@unipd.it
} 


\section{Introduction}

The reflections on the nature of consciousness and soul date back to the beginning of philosophy in both the East and the West and probably extend to pan-Asiatic prehistoric shamanism, both ancient philosophies and medicines derived from. The term consciousness has a wide range of meanings, like all terms related to subjective phenomena; as a result, albeit appearing familiar and conceptually clear, it can be hardly restricted in a comprehensive, simple definition. In fact, in the history of philosophy the concept of consciousness greatly overlapped with that of soul and ego. In the Western post-Cartesian thought they were assigned a different ontology with respect to the physical reality leading to their irreconcilable separation, a rationalistic guillotine splitting the mind-body - an inseparable unit in vivo - on the base of a priori metaphysical assumptions.

According to Jaynes, consciousness is diachronic, i.e., cannot be properly comprehended outside history and culture (Jaynes 2014, 1990), a fact in line with the wise definition of consciousness by William James, allowed by his pragmatist stance:

"It is that our normal waking consciousness, rational consciousness as we call it, is but one special type of consciousness, whilst all about it, parted from it by the filmiest of screens, there lie potential forms of consciousness entirely different. We may go through life without suspecting their existence; but apply the requisite stimulus, and at a touch they are there in all their completeness, definite types of mentality which probably somewhere have their field of application and adaptation. No account of the universe in its totality can be final which leaves these other forms of consciousness quite disregarded" (James 1917, 111).

Consciousness is an interdisciplinary topic, pertaining to anthropology, neurosciences, philosophy and physics, and posing an increasing need for an interdisciplinary approach. Medicine has a central role in defining the boundaries between health and disease, normality and pathology, including consciousness and its disorders. Despite the huge scientific development achieved in the past decades, medicine inescapably remains an inseparable mix of science and art, where the best scientific knowledge must blend with humanistic and ethical values - the Hippocrates' virtue - to properly recognize and treat diseases as well as understand and take care of the patient. Diagnosis has a central role in medicine, where the positivist-objectivist stance has been inclined to identify clear-cut limits between normality and pathology in the past. Nevertheless, the definition of disorders is a hard job endowed with relevant cultural and epistemological implications, especially when psychological and psychiatric functional disorders are concerned (Berganza, Mezzich, and Pouncey 2005; Wakefield 2010); this in turn entails a relevant risk of misdiagnosis and to take normal people for disordered ones (Frances 2013). For example, there are no clear-cut limits between grief and depression, while dissociative identity disorders (previously named multiple personalities) still include possession in the DSM-5, a fact showing their huge cultural, ethnic and epistemological implications (Stephenson 2015; APA 2013; Facco, Mendozzi, et al. 2019; Padmanabhan 2017). Furthermore, a huge variety of anomalous, ostensibly odd experience are nonpathological in nature and call for being properly understood, rather than psychiatrized. This makes the dichotomous classification of normality vs. pathology inappropriate and calls for admitting a large grey area of neither ordinary (viz., "normal") nor dysfunctional phenomena, the definition of which closely depends on the adopted Weltanschauung (view of the world) and Zeitgeist (spirit of times). They have been named in different ways, i.e., altered states of consciousness (ASCs), anomalous experiences (AEs), Exceptional Human Experiences (EHEs) and non-ordinary mental expressions (NOMEs), by different authors belonging to medicine, psychology and transpersonal psychology (Cardeña, Lynn J., and Krippner 2014, 2004; Palmer and Hastings 2013; Ludwig 1966; Facco, Agrillo, and Greyson 2015). ASCs have been faced from a strictly neurophysiological and psychobiological perspective in medicine (Boveroux et al., 2008; Vaitl et al., 2005), mainly conceiving them as a dysfunctional or anyway less-than-normal phenomena, thus skipping their psychological, cultural and existential implications. On the other hand, other authors have suggested the need for a revision of the very concept of ASC (Revonsuo, Kallio, 
and Sikka 2009). Given the huge overlapping between ASCs, AEs, and EHEs, as well as the incompleteness and/or incongruences present in their classifications, it is of paramount importance putting them under one roof, in order to allow for a coherent, rigorous interdisciplinary approach. In this article we shall use the term NOMEs to indicate them overall (their variety is listed in Table $1)$.

\section{Table 1: Main Non-Ordinary Mental Expressions}

- Alien abduction experiences

- Experience of other identities

- Hallucinations and visions

- Extrasensorial perceptions

- Hypnosis

- Lucid dreaming

- Meditation

- Mystical experiences

- Near-death experience (NDEs)

- NDE-like experiences

- Out-of-body experiences

- Previous lives' memories

- Synchronicity

- Synesthesia

- Stigmata

- Superior states of consciousness

- Trance

- Unexplained healing

- Xenoglossy

The term non-ordinary clearly indicates the deviation from the adopted Weltanshauung rather than from a supposed "normality", while the term mental expression better fits the need to establish the role of mind, in the absence of which the plain experience alone may be meaningless or even source of disorders. NOMEs have challenged peoples, philosophers, priests, artists and physicians since time immemorial in all cultures, engendering a profound influence in the cultural development of the whole humanity; they were faced through an unseparated philosophical, medical and religious approach in the antiquity, where earthly and divine worlds were considered to be contiguous and in close communication to each other.

Mercia Eliade (Eliade 1972) defined shamanism as the "archaic techniques of ecstasy"; actually, shamanism may be understood as a complex knowledge/belief system developed over thousands of years, in an attempt to control the natural world and disease. Etymologically, the term "shaman" means "man of knowledge" and, since knowledge means power, "man of power", a concept akin to Francis Bacon's definition of science as power (Facco and Zanette 2017), and to the history of modern science as the history of the will to power (Severino 1980, 2016). Shamans, also defined medicine-men, have probed the whole reality - including both the visible and the invisible, ordinary and non-ordinary - in the attempt to understand the mysterious relationship between the inner and outer worlds, health and disease, life and death and take care of diseased people. Many experiences - such as communication with gods, revelatory and premonitory dreams, oracles and divine healings - have been considered normal and welcome for millennia, and still they are in other cultures, while the modern Western materialist thought has ordained their scientific inconsistency and falsity. On the other hand, this view is based on metaphysical assumptions: thus, it is advisable to shortly analyse their foundation, in order to check possible limits and pitfalls. 
Should it be the case, the whole topic could be reappraised from a wider perspective, encompassing a metaphilosophical and metascientific approach in the attempt to better comprehend their meanings and relevance, with the related implications in clinical practice.

\section{Historical and epistemological implications}

A critical analysis of the whole history of philosophy, science and medicine is a huge problem far beyond the aim of an article and the competence of the authors. Nevertheless, appraising a few essential aspects and trying to merge them in a nutshell may help better envisioning some crucial, questions involved in the scientific approach to consciousness and NOMEs.

As mentioned above, Eastern and Western philosophies derive from a common source, the prehistoric pan-Asiatic shamanism (Tonelli 2009; Kingsley 1999; Fung Yu-Lan 1958; Izutsu 1984). In ancient Greece, a possible connection route with shamanism was Pontic Olbia, a settlement of Miletus in the coast of the Black Sea from where it probably spread to the Ionian cities and Samos, where most pre-Socratic philosophers lived (Facco 2014, Ch. 9; Kingsley 1999; Tonelli 2009; Ustinova 2009). The connection between the East and the West was also favoured by trade and exchange of information between ancient Greece and India before the birth of pre-Socratic philosophy (Adorno, Gregory and Verra 2004, 7-9).

Ancient Greek culture is an inseparable blend of rational philosophy and mysteric doctrines, including oracles and initiation rites, all great personalities (including Plato and Aristotle) were admitted to. Therefore, one cannot properly understand Greek philosophy without taking into account its esoteric components shrouded in absolute secrecy; for example, Plato seems to have indirectly divulged some principle of Eleusis' Mysteries in his theory of ideas [30, pp. 15-48]. Oracles, initiation rites to Mysteries, and incubation in Asclepius temples probably derived from prehistoric shamanism. The process of initiation (órghia) included the katábasis (descent to the underworld) followed by the anábasis (ascent to the upper world), a path paralleling shamanic

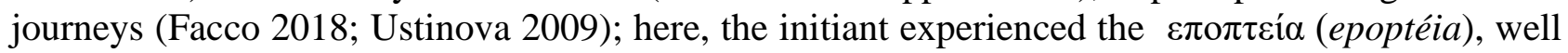
defined by Aristotle as follow:

"The thought of the intelligible, pure and simple, goes through the soul flashing like a lightning, offering, sometimes only once, the opportunity to touch and contemplate... Who has really touched the pure truth of it thinks he owns, as in an initiation, the ultimate end of philosophy". (Aristotle, Eudemo, Fr. 10; quoted by Scarpi 2012, 174-5).

Medicine was intimately connected to the sacred and, thus, to philosophy and religion, for over 3,000 years, from Imhotep temples in ancient Egypt to Ascelpius temples-hospitals in Greece, Hippocrates has been the most outstanding physician of. The non-dualistic paradigm held by both Hippocrates and Parmenides - who was also a philosopher-priest-physician, founder of the Eleatic medical School (Facco and Tagliagambe 2020; Vecchio 2004) - was akin to Taoism ${ }^{2}$ and contemplated the reality and inseparability of the whole - o $\lambda$ ov $\phi \cup \sigma \varepsilon \circ \zeta$, (oloi physeos) - the

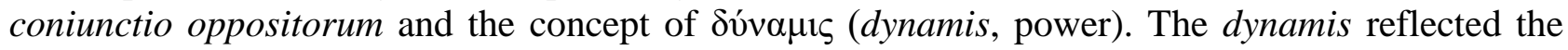
inseparable, dynamic interrelationship of mind-brain-body-environment, a surprisingly modern intuition of living beings as complex systems implying the need for a holistic approach, already well described by Plato in the Phaedrus (270b-e) as follows:

[Socrates] "...If we would proceed, not empirically but scientifically, in the one case to impart health and strength by giving medicine and food in the other to implant the conviction or virtue which you desire, by the right application of words and training... Hippocrates the Asclepiad says that the nature even of the body can only be understood as a whole".

With the advent of Christendom, the Asclepiad medicine was demolished by the hagiographic propaganda against paganism, and incubation only survived as the idea of miraculous healing in sanctuaries and churches, of which Lourdes is the last, most famous place. As a result, the technical, therapeutic procedure of incubation (to be considered as the ancestor of modern

\footnotetext{
2 There is a clear concordance between the Parmenides' concept of Being and Tao, as well as between his Light-Dark and the concept of Yin-Yang (Facco, Al Khafaji, and Tressoldi 2019; Facco and Tagliagambe 2020).
} 
hypnosis) was lost and reduced to matter of subject's faith and divine power only (Canetti 2010; Facco and Tagliagambe 2020; Mallardo 1949). Then, Thomas Aquinas' theology, by providing a rational foundation for religion, helped paving the way to the birth of the rationalistic revolution in the $17^{\text {th }}$ century and the birth of the new sciences.

The scientific revolution has been the cornerstone of the rational knowledge of the physical world in Western culture. Nevertheless, it was not born of a free epistemological reflection on what and how was to be investigated; rather, it was born of a political compromise with the Church, claiming its exclusive competence on the soul and theology. This resulted into what has been previously named the original sin of Galilean sciences (Facco, Agrillo, and Greyson 2015; Facco, Lucangeli, and Tressoldi 2017). In fact, Descartes was strongly concerned about avoiding an irreconcilable conflict with the Church. Therefore, in his Meditationes de Prima Philosophia (Descartes 1641) he demonstrated the existence of God and soul - a theory unavoidably based on circular reasoning and, then, assigned different ontologies to the res cogitans and res extensa, making them incommensurable. This was a sort of loophole allowing for the compromise with the Church, obtained at the cost of splitting what in nature was inseparably interconnected: in other words, the solution was a political parcelling, assigning the soul (consciousness) to the Church, and the physical world plus the earthen body machine to the science, safe from the Inquisition. Since then, the Cartesian split has not been considered worth of revision (Damasio 1994; Facco, Lucangeli, and Tressoldi 2017), while the Western thought has moved towards Enlightenment, Empiricism, Positivism and materialist monism, the mainstream science is based on. Nevertheless, materialism can be founded only if an autonomous, independent ontology of matter is metaphysically adopted and, in doing so, it maintains a latent dualistic stance. According to Severino, materialist monism is metaphysically self-contradictory, in that it a priori rejects what looks to be immaterial without demonstrating its inexistence; thus, it must implicitly admit it to allow for its refusal (Severino 2016; Facco, Lucangeli, and Tressoldi 2017; Facco and Fracas 2018).

Galileo himself in the Dialogue Concerning the Two New Sciences (Day 3, corollary 3), written following abjuration, reported that the self-limitation of science to the physical world was accepted obtorto collo (reluctantly):

"... But profound considerations of this kind [about he First Cause and the soul; Authors' note] belong to a higher science than ours [a più alte dottrine che le nostre]. We must be satisfied to belong to that class of less worthy workmen who procure from the quarry the marble out of which, later, the gifted sculptor produces [the theologian; Authors' note] those masterpieces which lay hidden in this rough and shapeless exterior. (Galilei 1638).

The new sciences were based on Galileo's mathematical apriorism (Burtt 2003), as he stated in the Dialogue Concerning the Two Chief World Systems - Day First :

"I say that the human intellect does understand some of them [propositions; Authors' note] perfectly, and thus in these it has as much absolute certainty as Nature itself has. Of such are the mathematical sciences alone... I believe that its knowledge equals the Divine in objective certainty" (Galilei 1632)

The Galileo's mathematical apriorism was very effective and successful in the investigation of the physical world, providing a mathematical quantitative model of causal relationships between facts. On the other hand, its exclusive use in living beings is questionable, in that it reduces them to a set of equivalent quantitative mathematical parameters only. In this cultural climate, medicine - the most humanistic of Galilean sciences - more and more focused on mechanical relationships of the Cartesian bodily earthen machine, reducing human beings to a sort of a small clock (e.g., La Mettrie's Machine Man 1747) surrounded by the big clock of Newtonian universe (an obsolete view in modern physics). This stance has led to Hippocrates and his concept of dýnamis being inadvertently betrayed (Facco and Tagliagambe 2020). As a result, the undeniable power of modern scientific medicine unravels and shows its inadequacy in front of subjectivity, which is the inescapable core of suffering, pain, distress, anxiety, depression and existential implications of severe diseases - i.e., the spectre of disability and perception of one's doom, which play a relevant role in palliative care (Facco et al. 2017). 
The principle of the Nonoverlapping Magisteria (S. J. Gould 1997) - held by Pope Pius XII in his encyclical Humani Generis (1950) and Pope John Paul II's proclamation of October 1996 - can be considered as the long term result of the forced compromise between the new sciences and the Church in $17^{\text {th }}$ century. It has also been endorsed by the National Academy of Sciences of the USA, which established that:

"Many scientists are deeply religious. But science and religion occupy two separate realms of human experience. Demanding that they be combined detracts from the glory of each" (Alberts 1998).

On the other hand, Gould himself recognized the limits of the principle of nonoverlapping magisteria:

"This resolution might remain all neat and clean if the nonoverlapping magisteria of science and religion were separated by an extensive no man's land ... In fact, the two magisteria bump right up against each other, interdigitating in wondrously complex ways along their joint border. Many of our deepest questions call upon aspects of both for different parts of a full answer" (S. J. Gould 1997).

Thus, the principle of Nonoverlapping Magisteria remains a mediocre political compromise, rather than a solid, epistemologically well-founded principle: it is constitutively unable to properly approach the huge problems rising at the surface of friction between science and religion, a fact routinely occurring in clinical practice when facing the above-mentioned conditions with their huge psycho-philosophical-existential implications. They cannot be solved within the limits of reductionism or other limited metaphysical apriorisms of whatever kind, while their management cannot be reduced to a more or less complex set of mechanistic interventions on the body machine; of course, these remain essential but, alone, are far from being enough. Finally, the abovementioned compromise spells out why scientific psychology was born only at the end of $19^{\text {th }}$ century - stemming from philosophy and not from medicine - with a delay of over two centuries form the birth of the new sciences. In early $20^{\text {th }}$ century, behaviourism denied the relevance of consciousness in psychology (Ferrari, Robinson, and Yasnitsky 2010), while the science of consciousness was born only in the 1980s' and its foundation has given rise to a huge, still ongoing epistemological and metaphysical debate.

\section{On the science of consciousness}

By definition, consciousness is an irreducibly subjective phenomenon, the contents of which can only be known by inner perception and shared with others through communication of the experience by first-person perspective (1PP); some essential aspects of the Self may be only approached by introspection as well (Facco, Al Khafaji, and Tressoldi 2019). Qualia, the phenomenal properties of sense data, include perceptual experiences, bodily sensations, felt reactions, passions or emotions, and felt moods (Tye 2018). They are a complex topic undergone a huge debate between physicalists and anti-physicalists involving several renown mental experiments, like those of Mary's room (Jackson 1982) and Zombie (Kirk 2019), posing still unsolved questions (Sturm 2012).

If qualia are generally considered as part of conscious experience, it should be taken into account that phenomenal experiences include both unconscious and conscious levels, ranging from anoetic to noetic ones, up to the level of self-reflexive experiences (Solms and Panksepp 2012), a fact common to both humans and many animals. The transition from anoetic to noetic experiences reflects a caudo-rostral integration in the brain, where the latter dresses the former with images, concepts and metaphors in order to be consciously experienced and make them communicable. Their essential feature is their qualitative meaning, despite quantitative features are also present; for example, pain is an exclusively subjective experience featured by a well-known specific quality, but its intensity is an essential quantitative part of the experience too.

The foundation of the science of consciousness has entailed a huge debate between materialist monists, considering it as a plain epiphenomenon of brain circuits, and those considered as dualists, who think that consciousness and qualia cannot be reduced to brain circuitry. Among these, Chalmers has well-defined the whole topic in terms of easy and hard problems (Chalmers 1999). 
The former is far from easy in itself, but is such in that the paradigm and method are available i.e., the reductionist approach aimed to understand the brain mechanisms associated to consciousness. The latter is the problem of qualia and is hard in that the paradigm and method of investigation are not available yet, and probably call for a shift of paradigm to properly include the world of subjectivity in science.

Some authors have hypothesized an unbridgeable explanatory gap between brain circuitry and consciousness, leading to physicalist claims being falsified due to the lack of entailment between them - i.e., neither the former can be deduced from the latter, nor the latter may logically supervene on the former (Levine 1983; Chalmers 1999). As a result, the gap would call for bridge laws able to properly connect the reduced theory to the reducing one. On the other hand, other authors think that a conceptual gap does not necessarily entail an explanatory gap and, thus, the problem can be solved by theoretical identifications (Marras 2005) or, anyway, bridge laws are not necessary at all (Morris 2009). Nevertheless, Marras has supported his argument pro theoretical identification with the example of pain, as follows:

For once we have got our theoretical identifications (inductively derived as they must be), it can't any longer be a mystery why C-fibers firing should feel like pain: C-fiber firing is pain; and it is a mystery that pain should feel like pain? As Kim earlier remarked, 'Identity takes away the logical space in which explanatory questions can be formulated"'.

Unfortunately for physicalists, pain is a very complex phenomenon that cannot be equated to Cfiber firing. The definition of pain by the International Association for the Study of Pain universally accepted in medicine and also adopted by the World Health Organisation ${ }^{3}-$ is the following (IASP 1979):

"An unpleasant sensory and emotional experience associated with actual or potential tissue damage, or described in terms of such damage."

This definition clearly states that pain is a matter of sensory and emotional experience, and properly avoids tying it to nervous pathways stimulation. This is tantamount to say "no experience, no pain", a fact implying that pain may be managed not only by painkillers but also by changing the experience. An outstanding proof is hypnotic analgesia, which may be as effective as to allow for surgery without anaesthetic drugs (Facco et al. 2013, 2011). It is the result of an intentional, introspective activity leading to pain neuromatrix in the brain being controlled and inputs from Cfibers to the somatosensory cortex being blocked (Casiglia et al. 2020, 2018): thus, a maximal stimulation of $\mathrm{C}$-fibers in the periphery may not be equivalent to even the slightest pain. This also shows the self-contradictory overriding attitude of reductionist medicine to relay on drugs only.

As a result, pain - despite ostensibly looking a plain physical symptom yielded by tissue injury can be better understood by moving beyond the narrow limits of the reductionist approach to encompass the abilities of subject's mind. The example of pain has been also used in the argument of truth-makers of perceived inner states (Fumerton 2005), though in a questionable way (see Facco et al. 2019b, for criticism). But chronic pain also entails huge psychological and existential implications that cannot be ignored in clinical practice. Le Breton has wisely defined pain from an anthropological standpoint as an incision of the sacred, ripping one from himself and leading to face one's limits, the transience of life and its cost: thus, pain obliges to metaphysics (Le Breton 2010, 2007).

The debate on reductionism in the philosophy of mind also includes the problem of reliability of measures of introspective activity, the uncertainty of which has led Elizabeth Irvine to wonder whether it is a methodological muddle to be abandoned or even calling for withdrawing consciousness from scientific practice (Irvine 2012b, 2012a). The problem is far from being new and has undergone a deep analysis in the past centuries in both Eastern and Western philosophies. It is well-known that introspection may be self-deceptive, given that the observer has a restricted perception of his/her inner world (ignoring all what is unconscious) and may alter the observation

${ }^{3}$ (http://www. health24.com/Medical/Pain-Management/About-pain/Definition-ofpain-2012072) 
of inner states. On the other hand, the validity of perception and understanding of the outer world is far from being unerring, as the very history of science clearly shows, a fact reflecting the more general evidence of human fallibility in the process of knowledge as a whole (Facco, Al Khafaji, and Tressoldi 2019). Anyway, behavioural measurements, despite useful and compatible with the objectivistic stance of science, are far from being enough and the knowledge of introspective data remain essential for an appropriate comprehension of experience (like pain), self-perception, selfawareness, and self-knowledge. Furthermore, the only way to hopefully recognize self-deception is through metacognition, which remains matter of introspection, inner third person perspective and critical analysis.

Given the subjective, qualitative nature of qualia, it is reasonable arguing that Galilean sciences could not properly investigate and understand them, due to the incompatibility of their foundation with the world of subjectivity. The distinction between primary (e.g., shape, size, position, stillness and movement) and secondary qualities (e.g., colours, smell, taste, sound) was introduced by Democritus first:

"There are two kinds of knowledge, one genuine, one bastard (or 'obscure'). To the former belong all the following: sight, hearing, smell, taste, touch" (Fragment DK68B11).

"Democritus says that none of the sensible things exist, but our apprehensions of them are empty states of the senses, and in the external world there is nothing sweet, bitter, hot, cold, white, black or anything else which appears to everyone, for these are names of our states" (Sextus Empiricus, Math. 2.8.184-185).

"We know nothing about anything really, but opinion is for all individuals an inflowing" (Fragment DK68B7)... "I know that I know nothing" (Fragment DK68B304).

The Democritus' definition of senses was acritically adopted by Galileo and Descartes, leading them to believe that the former was an objective property compatible with the mathematical model, while the latter (qualia) was not. This distinction was probably supported by their idea that the world was written in mathematical language (Burtt 2003) and that reality could be objectively known as it is, an assumption not without an element degree of naïve realism. Instead, Democritus, besides observing that so-called secondary qualities were "names of our states", asserted that genuine knowledge could be provided by sight, hearing, smell, taste, touch; at the same time he recognized that "none of the sensible things exists... and we know nothing about anything really", thus we can only have opinions. Therefore, Democritus' thought does not seem to hold a clear-cut separation between primary and secondary qualities. Rather, his wise view seems akin to the Buddhist concept of Śñyatā (vacuity), indicating that the reality in itself is void of the qualia by which we perceive and codify it - i.e., it consists of what remains once the modalities of perception, qualia, mental objects, images and categories are filtered out. This epistemically exemplary concept allows for a radical liberation from the naïve realism, inclined to take one's qualia and concepts for the phenomena in themselves, a concept also well defined by Kant's critical dualism as the natural illusion of humankind (Kant 1781). If this is the case, the distinction between primary and secondary qualities remains questionable, since they are similar as concerns both their neurocorrelates and the relationship between the observer and the observed phenomenon.

\section{The Observer effect}

The role of the observer has been submitted to scrutiny by quantum physicists, the only scientist who felt the need to study consciousness in early $20^{\text {th }}$ century and move towards a unified worldview.

Wolfgang Pauli held the need for reappraising the concept of consciousness to encompass its role in a unified worldview, leading him to start a long collaboration with Jung (Jung and Pauli 1952; Tagliagambe and Maliconico 2011; Tagliagambe, Fracas, and Facco 2020). As he stated,

"Evidently the progress of science must take such a course that the concept 'consciousness' will be replaced by a more general or better one" (Pauli to von Franze, 13/1/1952. The Pauli Letter Collection, CERN Archive IV/1; quoted by Gieser 2005).

The interest of quantum physicists for consciousness, started in early $20^{\text {th }}$ century, is still ongoing 
and several intriguing hypotheses of its quantum implications have been introduced. They include three main fields of interest:

a) Quantum mechanisms in neurons (Penrose 2016; Poznanski, Tuszynski, and Feinberg 2017), a topic pertaining to the nascent quantum biology (Lambert et al. 2013; Bordonaro and Ogryzko 2013; Melkikh and Khrennikov 2015; J. L. Gould 2015; Heyers et al. 2017).

b) Epistemological implications of quantum physics, i.e., the interpretation of mind properties according to its paradigm. For example, the process of making decisions has been better interpreted by quantum than classical probability calculation (Wang et al. 2014). Other authors have hypothesised a parallel between the mind-brain relationship and the quantum mechanical-classical property relationship (Martin, Carminati, and Galli Carminati 2010; Galli Carminati and Martin 2008); the relationship classical-quantum transition had been also hypothesized at synaptic level (Beck and Eccles 1992).

c) Hypotheses of a unified psychophysical world or a mental universe, also including the Jung and Pauli's concept of synchronicity (Atmanspacher 2015, 2013; Galli Carminati, Martin, and Carminati 2017; Barlow 2015; Neppe and Close 2015; Walach and Romer 2011; Tagliagambe, Fracas, and Facco 2020).

In short, the quantum implication of consciousness are both physically plausible and epistemologically sound, despite ostensibly incompatible with classical thought and, thus, cannot be a priori rejected. The whole of data discussed above is in line with the need for overcoming the limits and constraints of Descartes' radical dualism in the world of physics, in order to properly understand both quantum mechanics and consciousness, as emphasized by Appleby:

"To construct an adequate non-Cartesian philosophy would take an enormous amount of work. However, I believe there is reason to think that if we were to undertake that project it would lead to a conceptual revolution equal in magnitude to the 17th century Cartesian one. In particular, it would lead to conceptions of the world, and of human nature, which differed as much from the Cartesian conceptions as the latter did from medieval conceptions. So much so that we would, perhaps, no longer want to use the words "consciousness" and "matter" (except in their everyday senses, of course)". (Appleby 2013)

What Appleby holds from the perspective of modern physics perfectly fits with the above discussion borne in the science of consciousness, both highlighting the limits of the CartesianGalilean approach. Even more, we think that we should reappraise the post-Aristotelian thought, which has made his logic a dogmatic, undisputed doctrine (Russell 1959; Facco, Lucangeli, and Tressoldi 2017; Facco and Fracas 2018) and, following Plato's and Aristotle's parricide of Parmenides, has taken the original meaning of being for phenomenal existence - an ill-founded stance yielding Western nihilism (Severino 2016). This implies the need for rediscovering and fully comprehend the non-dualistic pre-Socratic thought, especially Heraclitus and Parmenides, who held the coniunctio oppositorum and their dynamic coevolution as manifestation (appearance) of being (the Parmenides' light/dark). Not surprisingly, this is akin to Taoism with its Yin/Yang polarity, also shared by Hippocrates in De Diaeta (I, 4, 9):

"Nothing arises from nothing, but everything changes due to mixture and separation, while men wrongly think that things come from the Hades and go back to the Hades: thus, they believe to their eyes, rather than reason... What is living cannot die... Is neither possible that what is not may start to be".

As a result, both pre-Socratic thought and Taoism are more compatible with quantum physics than Western classical thought; for example, the principle of reciprocal transformation of energy (Yang) and matter (Yin) had been already established by Taoism some three millennia ago.

The problems raised by the hard problem as well as the scientific revolution started by $20^{\text {th }}$ century physics, strongly suggest the need for a shift of paradigm and wondering whether a metaphilosophical and metascientific approach may help overcoming the limits of the ruling materialist-reductionist stance of neurosciences - a stance usually adopting the classical (by now obsolete) concept of matter. In this regard, one should be aware that reason is not the same as rationalism and science does not admit any unwavering faith in a given paradigm, i.e., a set of 
adopted axioms, theories, and beliefs. Here, it is worth mentioning an enlightened statement by Bertrand Russell for its relevance in philosophy, science and psychology (Russell 1912):

"All acquisition of knowledge is an enlargement of the Self... This enlargement of Self is not obtained when, taking the Self as it is, we try to show that the world is so similar to this Self that knowledge of it is possible without any admission of what seems alien... Knowledge is a form of union of Self and not-Self; like all union, it is impaired by dominion, and therefore by any attempt to force the universe into conformity with what we find in ourselves. This view... is untrue... What it calls knowledge is not a union with the not-Self, but a set of prejudices, habits, and desires, making an impenetrable veil between us and the world beyond. The man who has no tincture of philosophy goes through life imprisoned in the prejudices derived from common sense, from the habitual beliefs of his age or his nation, and from convictions which have grown up in his mind without the co-operation or consent of his deliberate reason".

\section{About reductionism, metaphysics and blind sight}

According to van Riel and Gulick (2019), reductionism entails the relation between entities and theories and is an ontologically neutral position in itself, despite being strongly linked to materialism and physicalism in modern science; therefore, it might also be applied to ostensibly or actually nonphysical aspects of the world. In other words, even the idealist and the Berkeley's immaterialist positions might be considered as a form of reduction from matter to mind; as a result, one should wonder whether the materialist scientific reductionism is only a possible option stemming from an a priori choice of the adopted set of axioms. The same is for consciousness.

Pain has been seldom used to explain the concept of reduction, as Nagel did with the example of headache - i.e., it may be explained by a detailed physical, chemical, and physiological complex of conditions for its occurrence (Nagel 1961; van Riel and Van Gulick 2019). Indeed, the definition of headache in neurology is in line with it and establishes that migraine is a complex neurovascular disorder including genetic, neurophysiological and neurochemical causes, and anatomical and physiological features (Charles 2018). This is undoubtedly true but conditioned by the materialist stance, leading to psychological and psychosomatic components being skipped. Therefore, it remains a partial self-limited despite valuable view and, as such, potentially unsuitable for a proper comprehension and management; in fact, both acupuncture and hypnosis, disregarded by mainstream medicine, have proved to be effective in its treatment (Flynn 2018; Linde et al. 2016, 2009).

The idea that any psychological and biological phenomenon may be explained by disclosing its most basic physical mechanisms is also questionable, if one takes into account that all living beings and Nature on a whole are complex systems and, as such, are endowed with emergent properties and capacity for adaptation and self-transformation. The fact that an emergent property of a system is a feature of the system as a whole but is not a property of any of its components poses legitimate doubts about the reductionist claim of plain reducibility of living beings to their physical basic mechanisms, as well as consciousness to brain circuitry. It also poses legitimate doubts about the appropriateness of the ruling deterministic approach of medicine to what may show chaotic, unpredictable behaviours and is subject to ongoing self-transformation and self-organization in the dynamic relationship with the environment (the Hippocrates' dynamis) (Bedau 1997; Cohen 2016; Eeles, Teodorczuk, and Mitleton-Kelly 2018; Howsepian 1997; Kuziemsky 2016; Ma'ayan 2017). In this context, it is worth clarifying that the authors are neither reductionists nor antireductionists. In fact, reductionism is a powerful method that has allowed for a huge knowledge of causal relationships between facts and mechanisms at the base of complex phenomena, including those investigated by neurosciences. On the other hand, it is only a method to be used when appropriate; thus, one should refrain from inadvertently turning it into ontology - i.e., the inclination to think that only what is understandable with it is worth being investigated and real, a stance prone to dogmatic drifts.

The century old debate between opposite metaphysical standpoints - i.e., reductionism vs. antireductionism, materialist monism vs. dualism, realism vs. idealism - is also involved in the 
science of consciousness. Rather than being a matter of irreconcilability and superiority of any in the assessment of truth, it reflects their intrinsic limits, being each of them unavoidably based on partial, though valuable, metaphysical principles. Their ostensible incompatibility also stems from the Western logical strategy of reasoning based on Aristoteles' logic, born to achieve rigorous demonstrations and, thus, settle disputes between different opinions. However, its value as well as the human capacity to judge and know the essence and substance of phenomena have been overrated in the past (Facco, Lucangeli, and Tressoldi 2017; Facco and Fracas 2018). The principle of non-contradiction, considered for centuries as the firmissimum omnium principiorum, is selfcontradictory over time. Actually, everything is doomed to change and become something different and, finally, disappear - making the concept of identity an unsolved philosophical conundrum (Facco, Al Khafaji, and Tressoldi 2019) - while quantum physics has demolished it to its roots by observing the dual nature particle-wave of photons (Merli, Missiroli, and Pozzi 1974).

In other words, Nature disregards clumsy attempts of humans to know it by imposing a priori established criteria, mental categories and rules, and constraining it within the narrow limits of the adopted perspective in the illusion of an "objective" knowledge. This inclination has an analogy with the physiology of sight, which is based on a narrow clear vision (some $1-2 \%$ of the visual field) surrounded by a blurred field; even if a clear, full visual field would be available, nothing existing outside it could be seen. As a result, seeing - with both sight and mind - closely depends on the limited field of view: thus, it means being blind at the same time. Metaphorically, it recalls the blind sight due to cortical blindness, where patients are able to respond to some visual stimuli they cannot see and are not conscious of. In both everyday life and science we adapt to reality only perceiving a small part of it and neglecting what is not perceivable and/or understandable, but with the duty to grasp it in order to improve knowledge, i.e., making the invisible visible. Thus, an inflexible adoption of any single point of view, paradigm or discipline is at high risk of remaining partially blind and lose the great opportunity to move towards the Russell's enlargement of Self. This has been well-painted by a renown anecdote dealing with a man under a street lamp looking for the house keys he lost elsewhere, because that was the only place where he was able to see.

\section{Towards a metaphilosophical and metascientific approach.}

As mentioned above, the appearance of consciousness in the world, as well as its development probably started tens thousands years ago with an event named the Sapient Paradox by Darwinian anthropologists, given that human DNA has been much the same since about 100,000 years ago (Facco and Zanette 2017). The ostensible paradox stems from the reductionist stance, only taking into account genetics while skipping culture; it has given rise to a debate between mainstream and cognitive anthropologists, akin to the one between materialist monists and so-called dualist in the science of consciousness. Given that the diachronicity of consciousness (including NOMEs) and its development is independent of detectable DNA changes, it cannot be properly comprehended from a narrow materialistreductionist standpoint neglecting the role of mind, experience and culture. Rather, it calls for a wider multidisciplinary approach - integrating medicine, psychology, anthropology, philosophy and physics in a whole - in order to encompass the mind-brain-body and innerouter world relationships. If this is the case, the worldwide transcultural and transtemporal presence of consciousness, might be better faced by a metaphilosophical and metascientific approach in the hard job of comprehending its nature and its place in the world. It is worth emphasizing that metascientific does not mean non-scientific; indeed, it may be part of a rigorous scientific way aimed to overcome the intrinsic limits of any single discipline.

Generally speaking, it is reasonable thinking that limited ethnocentric perspectives be no longer tenable in a globalized world; cultural differences should not be anymore conceived as sources of discrimination, but be appraised as sources of cultural enlargement, widening one's perspective and allowing for a better understanding between peoples (Jullien 2016). As previously reported (Facco, Al Khafaji, and Tressoldi 2019), a proper approach to transcultural 
phenomena calls for a metaphilosophical approach in the attempt to overcome ethnocentric cultural filters and constraints yielded by the Weltanschauung and the Zeitgeist one belongs to. Actually, most of what pertains to both ancient Western and Eastern cultures may be inadvertently deemed as irrelevant, ostensibly odd or anyway a product of a more primitive naïve thought, especially when it ostensibly contradicts what seems not compatible with the adopted ethnocentric and chronocentric perspective. Metaphilosophy can be defined as the philosophy of philosophy - viz., the investigation of the nature of philosophy (Lazerowitz 1970), dealing with the nature and possibility of knowledge and understanding (Overgaard, Gilbert, and Burwood 2013). In other words, it is the inquiry into the nature of philosophical questions and proper methods to investigate them.

Some principles compatible with metaphilosophy were present in the history of ancient philosophies and religions, when the knowledge of the world contemplated creation, life, physical reality and human mind as constitutive parts of one undivided world. In the West, some elements of such a monist view encompassing and unifying everything may be found in different philosophers, from Pre-Socratic ones, to Plato, Neoplatonists, Steuco, Leibniz, Spinoza, and Idealism. This view can be also found in the conception of Unus Mundus by Gerardus Dorneus (1530-1584) - the outstanding alchemist whose thought has been well analyzed by Jung (1980). In $20^{\text {th }}$ century it was held by Aldous Huxley in The Perennial Philosophy (Huxley 1946) and in the Henry Corbin's dialogue dans la méta-histoire, gathering historiography and the meaning of history in the great movements of humankind (quoted by Izutsu 1984).

The metaphilosophical perspective aims to recognize key concepts and meanings common to different philosophies beyond their formal differences and different modes of theorization, where the common field of reflection is aimed to find the problem's unity in the multiplicity of forms. Metaphorically, it is tantamount to seek for "roots rather than fruits" (Hut 2004) or walking down to the bottom of canyons, rather than trying to build bridges on their peaks. The search of roots implies the connection rather than the separation of the examined worlds, the latter inclined to simply check differences to discriminate and reject what is not compatible with one's perspective.

Thus, metaphilosophy is quite different form the Oursel's comparative philosophy based on a neutral, positivist, ethnocentric stance (Oursel 1923), born in an epoch marked by the selfclaim of the superiority of Western white man and the opprobrious consequences of colonialism and ideologies of early $20^{\text {th }}$ century. Instead, it holds the need for getting out of one's comfort zone and enter a heterotopic common field of reflection to properly understand other cultures from inside and reappraise the foundations of Western thought (Burik 2009; Weber 2013; Jullien 2015). It is a hard, epistemologically sound job calling for a mix of neutrality, openness and capacity to properly understand and absorb valid concepts drawn from different cultures, even when they seem ostensibly odd, and make them a food for self-transformation. The concept of metaphilosophy is in line with that of metascience, an interdisciplinary approach belonging to the most rigorous scientific stance, to be adopted in order to overcome the intrinsic limits of single axiomatic disciplines.

The Theorems of Incompleteness introduced by Gödel in the 1930' have shown the limits of provability in formal axiomatic systems (see Raatikainen 2018 as a review). The first theorem states that any consistent formal mathematical system necessarily include undecidable statements which can neither be proved nor disproved, viz., it is incomplete. The second one states that these consistent formal systems cannot prove from their inside that the systems themselves are consistent, i.e., the consistency of a theory is something the theory by itself cannot prove. Therefore, theories are intrinsically incomplete, despite including a set of axioms and the proof relation of the given formalized system to make them decidable.

The problem of incompleteness recalls logic paradoxes, like the Lyar's, which is also mentioned in St. Paul's letter to Titus $(1,12)$ including a naïve assertion of its truthfulness: 
"One of themselves, even a prophet of their own, said, the Cretians are always liars, evil beasts, slow bellies. This witness is true".

There are several logically unsolvable paradoxes, like the Russell's paradox (or antinomy), the paradox of the barber (also introduced by Russell), and the theological conundrum of St. Christopher, mentioned by Freud (Freud 1921):

"Christopher bore Christ; Christ bore the whole world; Say, where did Christopher then put his foot?".

The Russell's paradox (also known as Russell's antinomy), introduced in 1902, questioned both Cantor's naïve set theory and Frege's logic system. Russell proved the idea that the set of all sets not including themselves as members is self-contradictory - i.e., it is a member of itself if and only if it is not a member of itself. This contradiction is exemplified by the barber's paradox - defined as one who shaves all those, and those only, who do not shave themselves: then, who shaves the barber? Neither himself nor others.

In general, logical paradoxes are based on self-referentiality, where the sentence tells about itself that it is not true, resulting in the assertion that the proposition $\mathrm{p}$ is at the same time true and false (p $\wedge \neg \mathrm{p}$ ) - or that it is neither true nor false - but the Gödel's theorems show that it is not necessarily so. Within classical thought, Duns Scoto gave in on the conclusion that when the logical contradiction is not solvable, one can do what one likes (ex absurdo, sequitur quod libet).

The Gödel's theorems deal with formal logic system and mathematics, while their extensions to other disciplines is more controversial. Nevertheless, it sets some constraints in empirical sciences too, from astrophysics to life sciences - especially in the study of consciousness and subjectivity showing that these sciences are not enough to provide demonstrations endowed with mathematical certainty (Buechner 2010); as a result, one must feel happy with lower than optimal certainty (as provided by statistical analysis). As a further option, knowledge may be improved nonmathematically by enlarging the theory with epistemically sound non-mathematical principles, and/or moving towards an interdisciplinary integration. This is in agreement with the second Gödel's theorem - i.e., the fact that the consistence of a formal system cannot be demonstrated from inside the system and, thus, it calls for an extension to a more powerful system. Anyway, the Gödel's limitations only warn against the claim of mathematical certainty of demonstration, a fact only seldom achievable in life sciences, if possible.

An interesting example of the inclusion of extrascientific principles in science is the anthropic principle in astrophysics, of which a weak and a strong form have been introduced (Carter 1974, 2011; Rebaglia 1996; Barrow and Tipler 1988). The weak form is the following:

"Weak Anthropic Principle (WAP): the observed values of all physical and cosmological quantities are not equally probable but they take on the values restricted by the requirement that there exist sites where carbon-based life can evolve and by the requirement that the Universe be old enough for it to have already done so."

The strong version is the following:

"Strong Anthropic Principle (SAP): the Universe must have those properties which allow life to develop within it at some stage in its history."

There are also two more speculative versions, the participatory and the final anthropic principles. The former states that not only the universe had to develop humanity but that we are necessary to its existence, as it takes an intelligent observer to collapse the Universe's waves and probabilities from superposition into relatively concrete reality. The latter states that once intelligence has come into being, it will never die out.

All versions of the anthropic principle include empirical extrascientific assertions supporting a theory and helping a connection between the "antecedent" and the "subsequent" (Rebaglia 1996), i.e., the physical conditions and the biologic constraints that may help defining the range of cosmological constants compatible with the presence of biological life and human kind on the earth. Being not scientific in nature, the anthropic principle does not result into a teleological interpretation; rather, it engenders a meta-level, allowing to overcome the limits of the discipline it 
refers to and, in this regard, it may be considered as an epistemological consequence of Gödel's theorems.

As mentioned above, the application of Gödel's theorems to disciplines other than mathematics such as philosophy and neurosciences remains a matter of debate, but it clearly lessens the Galilean "mathematical certainty". As discussed above, the paradigm of the new sciences was born to study physical phenomena only, making it reasonable arguing that it cannot properly investigate consciousness and the mind-brain-body relationship. If this is the case, a metaphilosophical and metascientific approach may be appropriate in the study of consciousness and subjective phenomena, since the 1PP and the meaning of the experience are the conditio sine qua non for their proper understanding.

As regards reductionism, the above-mentioned reflections on identities and bridge laws are relevant to check its strengths and limits, a fact of paramount importance for both reductionists and antireductionists. On the other hand, an inflexible, materialist-reductionist approach is questionable according to both Aristotle's Metaphysics and quantum physics. In fact, Aristotle clearly warned against adopting axioms without constantly wondering about their truthfulness, in order to avoid dogmatic drifts (Metaphysics, 1005b, 1-5). According to quantum physics, matter is no longer the primary aspect of the world; rather, it is made of vacuum-energy-information and interrelated events, where matter emerges from the vacuum as a concentration of energy, and, thus, is a secondary product (Wilczek 2010), while the observer is an inseparable part of the observed phenomenon.

Two key concepts define consciousness and the mind-brain relationship in neurosciences:

a) Consciousness as an emergent property of brain complexity;

b) The close relationship between mind and brain - i.e., any mental state, process and product is associated to specific neurocorrelates.

Granted these concepts, no activity of mind and consciousness may occur without the activation of the corresponding brain circuits. There is no problem in accepting it, but correlation is not synonymous of causality, and, even in that case, it cannot anyway be a priori reduced to a unidirectional bottom-up hierarchy only.

As concerns the concept of emergent property, it is a feature of complex system, implying the appearance of supervenenent properties not detectable in its components, leading to the fallacy of division and reduction. For example, the knowledge of muscle fibers is essential to understand their contractility and heart function, but, alone, it cannot explain the cardiac pump, which depends on their assembly and synchronization: therefore, in ventricular fibrillation all myocytes go on contracting but the pump is out of work, leading one to sudden death. Likewise, brain localizationism (heir of Gall's phrenology), despite useful and effective to disclose critical areas of circuits involved in mental functions, cannot provide a satisfactory explanation of them as a whole. The case of consciousness is the most intriguing, since there is no area of consciousness in the brain. Rather, it emerges as a complex interrelationship of many, still ill-defined areas and circuits, including the ascending reticular activating system, the thalamo-cortical and cortico-cortical connections, where the interface and transduction between brain circuitry and the related mental events with their qualia (how they turn into each other) is unknown. We do not know whether in the future a complete set of mind-brain identities will be so well defined as to allow for achieving physicalist claims, but certainly this is a goal far from being at hand, if possible.

The mind-brain relationship - should be it so close as to be biunivocal - may only establish the correlation, while turning it into a bottom-up exclusive causality is not logically allowed, since it is based on materialist, plausible but undemonstrated axioms. Once the biunivocal correspondence is admitted, a bidirectional bottom-up and top-down causation is more plausible, a fact also compatible with the neutrality of reductionism. The latter is akin to phenomenal experience, and the perception of being the agent of our choices, be they dependent on conscious decision or started at an unconscious level. The former is the reductionist perspective, where the concept of mind as a plain epiphenomenon of brain circuitry leads to its role and meaning being neglected. In other 
words, one should wonder whether the above-mentioned debate between materialist monists an dualists in the science of consciousness is a matter of Gödel's indecidability and, as a result, plausibility of both. Following the full completion of materialist reduction, the world of mind with its meanings would disappear and only brain circuits, electrical activity and neurotransmitter would remain available. If so, philosophy and science themselves, being products of mind living in the world of consciousness, would cease to exist as well.

On the other hand, the top-down causation is a real fact, where words and sensory stimuli may behave as a sort of neurotransmitters yielding specific changes in the brain. The whole of literature on functional magnetic resonance in hypnosis and meditation clearly shows how mind is able to yield intentional activations/deactivation of unconscious brain areas through introspection and reach outstanding goals, one for all the above-mentioned hypnotic analgesia (Facco 2014; Casiglia et al. 2020; Facco et al. 2013; Derbyshire et al. 2004).

If the above discussion is correct, one should move beyond any inflexible, partial stance - be it materialist or not, reductionist or anti-reductionist, or anything else - and avoid to a priori project ethnocentric and anthropocentric prejudices, axioms and mental categories into the outer world with the illusion of knowing it "objectively". Instead, the proper way to knowledge should follow the exemplary concept of Russell's enlargement of the Self reported above. Reductionism remains a powerful and effective tool to investigate causal relationship between physical events; the error is claiming its absolute value and a priori rejecting anything ostensibly incompatible with it, a stance recalling Church's exclusivism in $17^{\text {th }}$ century.

\section{Conclusions}

The issues discussed above are in line with the theory of the three worlds by Popper and Eccles, we hold a modified version of (Popper and Eccles 1977; Facco, Lucangeli, and Tressoldi 2017; Facco and Fracas 2018). In this model, world 1 is the physical reality, world 2 is the mind-brain unit (the transducer and processor of inputs form world 1), and world 3 is the world of mind, including its products and unconscious processes (Figure 1).

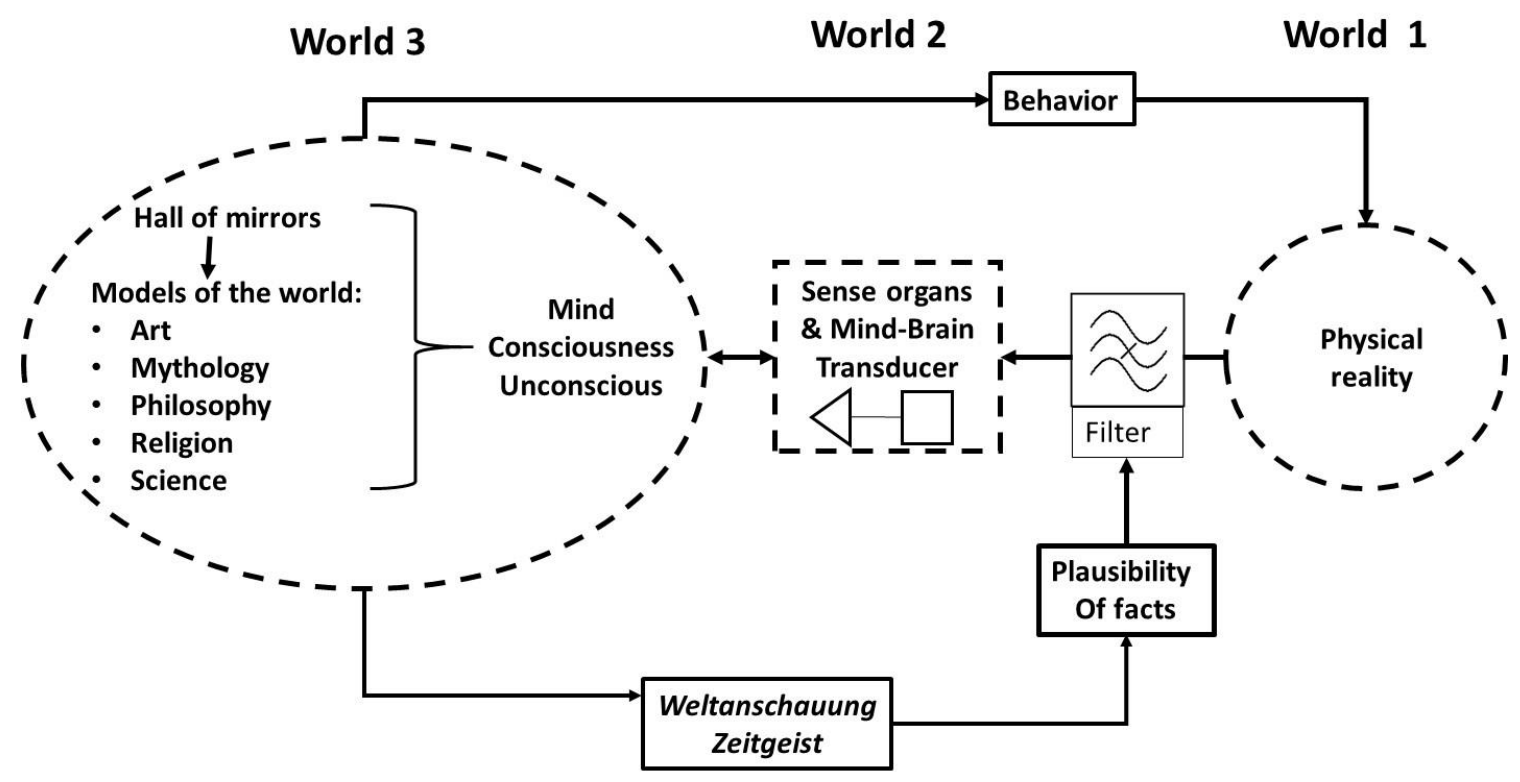

Figure 1: Schematic representation of the relationship between the outer world, the mind-brain unit, and the inner world, including the process of knowledge and the reciprocal influence between inputs from the outer world and its models. 
It shows that the outer world, as we perceive and know it, is not the same as phenomena in themselves, being made of their images and representations (this the reason for calling it the hall of mirrors, in that it "reflects" the outer world). As a result, the world is an inescapable co-creation of the physical reality and the human mind, the latter representing the former.

The perception of reality is weaker than commonly believed, because the available information is necessarily partial, while the features of sense organs (with their limits and filters) and brain coding processes are unconscious, leading to the illusory naïve realism of ordinary consciousness (i.e., the belief that the senses provide us with direct awareness of objects as they really are). If so, the debate between realists and idealists seems flimsy, because both physical and subjective aspects form an inseparable whole in the interpretation of reality, where everything belonging to the materialist view is made of the stuff of mind, where the so-called objectivity cannot trespass the level of shared subjectivity. If this is the case, materialism might result to be more "idealist" than believed, being itself a product of mind and dealing with mental images of the physical world.

The inseparable mind-world relationship may be approached according to phenomenology, starting form Heidegger's Dasein ("being there" or "presence") as the basic, immediately given condition of the existence in the world from which one cannot give up, making consciousness and experience non-eliminable - i.e., no consciousness no world, at least as one can know it. It looks much simpler and more tangible than a rationalist, abstract conceptualization a priori splitting mind and matter, and discarding the former on the base of a purported logical incompatibility. In his introduction to dialetheism, Priest [1998]) provocatively entitled his article "What is so bad about contradictions?". Likewise, granted the ontological neutrality of reductionism (van Riel and Van Gulick 2019), we may paraphrase Priest's article saying: what is so bad about assigning the foundation (or co-foundation) of the world to consciousness?

Since the beginning of $21^{\text {th }}$ century, an increasing dissatisfaction with the eliminative materialist stance has paralleled the need for reintroducing subjectivity in medicine (Zeman 2001) and a neurophenomenological approach has been discussed in an increasing number of papers (e.g., Cardeña et al. 2013; Facco et al. 2019a,b; Ionta et al. 2011; Salomon et al. 2013)

If the study of consciousness seems to engender a methodological muddle to be abandoned, or even calling for withdrawing consciousness from scientific practice (Irvine 2012b, 2012a), it is not a problem of science in itself but only of the materialist-reductionist approach; thus, one should wonder whether the latter should be changed, rather than consciousness be withdrawn from science. The explanatory gap between brain circuitry and experience stems from brain complexity - some 100 billions neurons, each connected to other neurons through hundreds synapses, plus glia cells (also involved in synaptic function, myelin formation and transmission of neural inputs), making the brain a connectome of incalculable complexity. Furthermore, brain is a plastic, dynamic organ, able to change itself through processes of pruning and sprouting of new neurons and synapses throughout life to allow for an effective adaptation. The whole of these features allow for human consciousness and the development of Self, as well as the appearance of some form of consciousness in many animals. Consciousness is embodied in life in an unceasing exchange of information with the unconscious and is closely related to personal identity and Self, making it a unique individual entity. Therefore, its uniqueness makes very difficult, if possible, its reductionist analysis. Despite being not mysterious in itself, this complexity makes the explanation really a hard problem, difficult to define in a discrete or parsimonious manner even when its reduction is in principle admitted (Feinberg and Mallatt 2019).

Finally, it is worth emphasizing once again that the eliminative materialist stance, denying any value to consciousness and subjective phenomena, cannot understand human features like the Self as well as relevant clinical phenomena like suffering and pain, which remain private facts lying beyond the limits of the objectivist stance of positive sciences. Nevertheless, they are neither less real nor less relevant than their neurocorrelates and behavioural aspects of psychological functions, making the materialist perspective self-contradictory and self-destructive. Actually, once 
consciousness has been reduced to brain circuitry and neglected as an immaterial, irrelevant or unreal phenomenon (the Ryle's ghost in the machine (Ryle 1949), for the sake of coherence one should silence forever; if this is the case, consciousness should be given back its meaningful central role in human life. 


\section{References}

Adorno, F, T Gregory, and V Verra. 2004. Manuale Di Storia Della Filosofia. Bari: Edizioni La Terza.

Alberts, B. 1998. "Science and Creationism. A View from the National Academy of Sciences. Preface.” In National Academy of Sciences Staff. , viii-ix. Washington: National Academic Press.

APA. 2013. Diagnostic and Statistical Manual of Mental Disorders, 5th Edition: DSM-5. Arlington, US: American Psychiatric Association.

Appleby, D M. 2013. "Mind and Matter." Cornell Univeristy LIbrary - Hystory and Philosophy of Physics, 1-26. arxiv:1305.7381v1 [physics.hist-ph].

Atmanspacher, H. 2013. "At Home in the Quantum World." Behav Brain Sci. 36 (1469-1825 (Electronic)): 276-77.

_. 2015. "Quantum Approaches to Consciousness.” In The Stanford Encyclopedia of Philosophy., edited by E N Zalta.

Barlow, P W. 2015. "The Natural History of Consciousness, and the Question of Whether Plants Are Conscious, in Relation to the Hameroff-Penrose Quantum-Physical 'Orch OR' Theory of Universal Consciousness.” Commun.Integr.Biol. 8 (1942-0889 (Electronic)): e1041696.

Barrow, J D, and F J Tipler. 1988. The Anthropic Cosmological Principle. Oxford, UK: Oxford University Press.

Beck, F, and J C Eccles. 1992. "Quantum Aspects of Brain Activity and the Role of Consciousness.” Proc.Natl.Acad.Sci.U.S.A 89 (0027-8424 (Print)): 11357-61.

Bedau, M A. 1997. "Weak Emergence.” In Philosophical Perspectives: Mind, Causation, and World., edited by J Tomberlin, 375-99. Malden, MA, USA: Blackwell Publishing Inc.

Berganza, C E, J E Mezzich, and C Pouncey. 2005. "Concepts of Disease: Their Relevance for Psychiatric Diagnosis and Classification.” Psychopathology 38 (0254-4962 (Print)): 166-70.

Bordonaro, M, and V Ogryzko. 2013. "Quantum Biology at the Cellular Level--Elements of the Research Program.” Biosystems 112 (1872-8324 (Electronic)): 11-30.

Boveroux, P, V Bonhomme, M Boly, A Vanhaudenhuyse, P Maquet, and S Laureys. 2008. "Brain Function in Physiologically, Pharmacologically, and Pathologically Altered States of Consciousness." Int.Anesthesiol.Clin. 46 (1537-1913 (Electronic)): 131-46.

Breton, D Le. 2007. Antropologia Del Dolore. Sesto San Giovanni, MI: Meltemi. . 2010. Esperienze Del Dolore. Tra Distruzione e Rinascita. Torino: Raffaello Cortina Editore.

Buechner, J. 2010. "Are the Godel Incompleteness Theorems Limitative Results for the Neurosciences?” J Biol.Phys. 36 (1573-0689 (Electronic)): 23-44.

Burik, Steven. 2009. "Opening Philosophy to the World: Derrida and Education in Philosophy." Educational Theory 59 (3): 297-312. https://doi.org/10.1111/j.1741-5446.2009.00320.x.

Burtt, E A. 2003. The Metaphysical Foundation of Modern Science. Mineaola, NY, US: Dover Publications. 
Canetti, L. 2010. “L’incubazione Cristiana Tra Antichità e Medioevo.” Rivista Di Storia Del Cristianesimo 7: 149-80.

Cardeña, E, P Jonsson, D B Terhune, and D Marcusson-Clavertz. 2013. "The Neurophenomenology of Neutral Hypnosis.” Cortex 49 (1973-8102 (Electronic)): 375-85.

Cardeña, E, S Lynn J., and S Krippner, eds. 2004. Varieties of Anomalous Experiences. 1st ed. Washington D.C., USA: American Psychological Association.

. , eds. 2014. Varieties of Anomalous Experiences. 2nd ed. Washington,DC, USA: American Psychological Association.

Carter, B. 1974. "Large Number Coincidences and the Anthropic Principle in Cosmology." In Confrontation of Cosmological Theories with Observational Data., edited by M S Longair, 291-98. Dordrecht, The Netherlands.: Reidel.

2011. "Republication of: Large Number Coincidences and the Anthropic Principle in Cosmology." General Relativity and Gravitation 43 (11): 3225-33. https://doi.org/10.1007/s10714-011-1258-7.

Casiglia, E, F Finatti, F Gasparotti, M R Stabile, M Mitolo, F Albertini, A M Lapenta, E Facco, V Tikhonoff, and A Venneri. 2018. "Functional Magnetic Resonance Imaging Demonstrates That Hypnosis Is Conscious and Voluntary." Psychology 9 (1571-1581).

Casiglia, E, F Finatti, V Tikhonoff, M R Stabile, M Mitolo, F Albertini, F Gasparotti, E Facco, A M Lapenta, and A Venneri. 2020. "Mechanisms of Hypnotic Analgesia Explained by Functional Magnetic Resonance (FMRI)." The International Journal of Clinical and Experimental Hypnosis 68 (1): 1-15. https://doi.org/10.1080/00207144.2020.1685331.

Chalmers, D J. 1999. The Conscious Mind. Oxford: Oxford University Press.

Charles, Andrew. 2018. "The Pathophysiology of Migraine: Implications for Clinical Management." The Lancet Neurology. Lancet Publishing Group. https://doi.org/10.1016/S1474-4422(17)30435-0.

Cohen, Alan A. 2016. “Complex Systems Dynamics in Aging: New Evidence, Continuing Questions.” Biogerontology 17 (1): 205-20. https://doi.org/10.1007/s10522-015-9584-x.

Colli, G. 2009. La Sapienza Greca. Milano, Italy: Adelphi.

Damasio, A. 1994. Descartes' Error. New York: G.P. Putnam.

Derbyshire, S W, M G Whalley, V A Stenger, and D A Oakley. 2004. "Cerebral Activation during Hypnotically Induced and Imagined Pain.” Neuroimage 23 (1053-8119 (Print)): 392-401.

Descartes, R. 1641. "Meditations on First Philosophy." In The Philosophical Works of Descartes., edited by E S Haldane. Oxford, UK: Oxford University Press, 1911.

Eeles, E., A. Teodorczuk, and E. Mitleton-Kelly. 2018. "Reconceptualizing Delirium as a Disorder of Complex System Failure." Medical Hypotheses 118 (September): 121-26. https://doi.org/10.1016/j.mehy.2018.06.031.

Eliade, M. 1972. Shamanism: Archaic Techniques of Ecstasy. New York, NY, USA: Routledge and Kegan Paul.

Facco, E. 2014. Meditazione e Ipnosi Tra Neuroscienze, Filosofia e Pregiudizio. Lungavilla, PV, Italy: Altravista.

Facco, E., E. Casiglia, S. Masiero, V. Tikhonoff, M. Giacomello, and G. Zanette. 2011. "Effects of 
Hypnotic Focused Analgesia on Dental Pain Threshold." International Journal of Clinical and Experimental Hypnosis 59 (4): 454-68. https://doi.org/10.1080/00207144.2011.594749.

Facco, E., and F. Fracas. 2018. L'enigma Della Coscienza. Milano: Mondadori.

Facco, E., S. Pasquali, G. Zanette, and E. Casiglia. 2013. "Hypnosis as Sole Anaesthesia for Skin Tumour Removal in a Patient with Multiple Chemical Sensitivity." Anaesthesia 68 (9): 96165. https://doi.org/10.1111/anae.12251.

Facco, E., and G. Zanette. 2017. "The Odyssey of Dental Anxiety: From Prehistory to the Present. A Narrative Review." Frontiers in Psychology 8 (JUL): 1855, 1-15. https://doi.org/10.3389/fpsyg.2017.01155.

Facco, E. 2018. "Ipnosi ed esperienze di premorte nel continuum delle espressioni non ordinarie della mente.” IPNOSI, no. 1: 13-38. https://doi.org/10.3280/IPN2018-001002.

Facco, E, C Agrillo, and B Greyson. 2015. "Epistemological Implications of Near-Death Experiences and Other Non-Ordinary Mental Expressions: Moving beyond the Concept of Altered State of Consciousness." Medical Hypotheses 85 (1): 85-93. https://doi.org/10.1016/j.mehy.2015.04.004.

Facco, E, E Casiglia, B E Al Khafaji, F Finatti, G M Duma, G Mento, L Pederzoli, and P Tressoldi. 2019. "The Neurophenomenology of Out-of-Body Experiences Induced by Hypnotic Suggestions.” International Journal of Clinical and Experimental Hypnosis 67 (1): 39-68. https://doi.org/10.1080/00207144.2019.1553762.

Facco, E, E Casiglia, G Zanette, and I Testoni. 2017. "On the Way of Liberation from Suffering and Pain: Role of Hypnosis in Palliative Care." Ann.Palliat.Med., no. 2224-5839 (Electronic) (May): 1-12. http://apm.amegroups.com/article/view/14986.

Facco, E, B E Al Khafaji, and P Tressoldi. 2019. "In Search of the True Self." Journal of Theoretical and Philosophical Psychology 39 (3): 157-80. http://dx.doi.org/10.1037/teo0000112.

Facco, E, D Lucangeli, and P Tressoldi. 2017. "On the Science of Consciousness: Epistemological Reflections and Clinical Implications." EXPLORE: The Journal of Science and Healing 13 (3): 163-80. https://doi.org/10.1016/j.explore.2017.02.007.

Facco, E, E Casiglia, B E Al Khafaji, F Finatti, G M Duma, G Mento, L Pederzoli, and P Tressoldi. 2019a. "The Neurophenomenology of Out-of-Body Experiences Induced by Hypnotic Suggestions." International Journal of Clinical and Experimental Hypnosis 67 (1): 39-68. https://doi.org/10.1080/00207144.2019.1553762.

Facco, E, L Mendozzi, A Bona, A Motta, M Garegnani, I Costantini, O Dipasquale, et al. 2019b. "Dissociative Identity as a Continuum from Healthy Mind to Psychiatric Disorders: Epistemological and Neurophenomenological Implications Approached through Hypnosis." Medical Hypotheses 130 (109274). https://doi.org/10.1016/j.mehy.2019.109274.

Facco, E, and S Tagliagambe. 2020. Ritornare a Ippocrate. Riflessioni Sulla Medicina Di Oggi. Milano, Italy: Mondadori.

Feinberg, Todd E., and Jon M. Mallatt. 2019. “Subjectivity 'Demystified': Neurobiology, Evolution, and the Explanatory Gap." Frontiers in Psychology 10 (JULY). https://doi.org/10.3389/fpsyg.2019.01686.

Ferrari, M, D K Robinson, and A Yasnitsky. 2010. "Wundt, Vygotsky and Bandura: A CulturalHistorical Science of Consciousness in Three Acts." Hist Human Sci. 23 (0952-6951 (Print)): 
95-118.

Flynn, Niamh. 2018. "Systematic Review of the Effectiveness of Hypnosis for the Management of Headache." International Journal of Clinical and Experimental Hypnosis 66 (4): 343-52. https://doi.org/10.1080/00207144.2018.1494432.

Frances, Allen. 2013. "The New Crisis in Psychiatry." Annals of Internal Medicine. https://doi.org/10.7326/0003-4819-159-3-201308060-00655.

Freud, S. 1921. "Group Psychology and the Analysis of the Ego." In The Standard Edition of the Complete Psychological Works of Sigmund Freud. Volume XVIII. London, UK: The Hogarth, 1994.

Fumerton, Richard. 2005. "Speckled Hens and Objects of Acquaintance." Philosophical Perspectives 19: 121-38. http://www.jstor.org/stable/3840891.

Fung Yu-Lan. 1958. A Short History of Chinese Philosophy. New York, NY, USA: The Macmillan Company. https://archive.org/details/in.ernet.dli.2015.260423/page/n1.

Galilei, G. 1632. Dialogue Concerning the Two Chief World Systems: Ptolemaic \& Copernican. Oakland, CA, US: University of California Press, 1967.

Galli Carminati, G, and F Martin. 2008. "Quantum Mechanics and the Psyche." Physics of Particles and Nuclei 39 (4): 560-77.

Galli Carminati, G, F Martin, and F Carminati. 2017. "A Very Simple Quantum Model of Mind and Matter." NeuroQuantology 15 (2): 186-99.

Gieser, S. 2005. The Innermost Kernel: Depth Psychology and Quantum Physics. Wolfgang Pauli's Dialogue with C.G. Jung. Berlin-Heidelberg, Germany: Springer.

Gould, J L. 2015. “Animal Navigation: Birds Have Magnetic Maps.” Curr.Biol. 25 (1879-0445 (Electronic)): R836-38.

Gould, S J. 1997. "Nonoverlapping Magisteria.” Nat.Hist. 16 (3): 16-22.

Heyers, D, D Elbers, M Bulte, F Bairlein, and H Mouritsen. 2017. "The Magnetic Map Sense and Its Use in Fine-Tuning the Migration Programme of Birds." J Comp Physiol A Neuroethol.Sens.Neural Behav Physiol, no. 1432-1351 (Electronic) (April).

Howsepian, A A. 1997. "Reductionism Revised: Return of the Biomedical Model." In Biopsychosocial Approaches in Primary Care: State of the Art and Challenges for the 21st Century., edited by H Leigh, 179-200. New York, NY, USA: Springer Sience+Business Media.

Hut, P. 2004. "Science in Seach of the World View." In The New Physics and Cosmology. Dialogues with the Dalai Lama., edited by A Zajonc. Oxford, UK: Oxford University Press.

Huxley, A. 1946. The Perennial Philosophy. London, UK: Chatto \& Windus.

IASP. 1979. "Pain Terms: A List with Definitions and Notes on Usage. Recommended by the IASP Subcommittee on Taxonomy." Pain 6 (3): 249. http://www.ncbi.nlm.nih.gov/pubmed/460932.

Ionta, Silvio, Lukas Heydrich, Bigna Lenggenhager, Michael Mouthon, Eleonora Fornari, Dominique Chapuis, Roger Gassert, and Olaf Blanke. 2011. "Multisensory Mechanisms in Temporo-Parietal Cortex Support Self-Location and First-Person Perspective." Neuron 70 (2): 363-74. https://doi.org/10.1016/j.neuron.2011.03.009.

Irvine, E. 2012a. Consciousness as a Scientific Concept: A Philosophy of Science Perspective. 
Dordrecht, The Netherlands.: Springer.

.2012b. "Old Problems with New Measures in the Science of Consciousness." British Journal of Philosophy of Science 63: 627-48.

Izutsu, T. 1984. Sufism and Taoism:A Comparative Study of Key Philosophical Concepts. Oakland, CA: University of California press.

Jackson, Frank. 1982. “Epiphenomenal Qualia.” The Philosophical Quarterly 32 (127): 127-36. https://doi.org/10.2307/2960077.

James, W. 1917. The Varieties of Religious Experience. A Study in Human Nature. Kindle Edi. New York, NY, USA: Longmans, Green, \& Co.

Jaynes, J. 1990. The Origin of Consciousness in the Breakdown of the Bicameral Mind. . Boston: Houghton Mifflin.

_2014. La Natura Diacronica Della Coscienza. MIlano: Adelphi.

Jullien, F. 2015. De l'Etre Au Vivre. Lexique Eurochinoise de La Pensée. Paris, France: Gallimard. . 2016. Il n'y a Pas d'Identité Culturelle Mai Nous Défendons Les Resources d'une Culture. Paris, France: Éditions de L’Herne.

Jung, C G. 1980. "Psychology and Alchemy." In Collected Works of C. G-Jung, Volume 12. Princeton, US: Princeton University Press.

Jung, C G, and W Pauli. 1952. Naturerklärung Und Psyche. Zurich: Rascher.

Kant, E. 1781. Critique of Pure Reason. Cambridge, UK: CAmbridge University Press (1998).

Kingsley, P. 1999. In the Dark Places of Wisdom. Poin Reyes, California: The Golden Sufi Center.

Kirk, R. 2019. “Zombies.” In Stanford Encyclopedia of Philosophy, edited by E N Zalta, 1-32. Stanford, CA, USA: Stanford Encyclopedia of philosophy. https://plato.stanford.edu/archives/spr2019/entries/zombies/.

Kuziemsky, Craig. 2016. "Decision-Making in Healthcare as a Complex Adaptive System." Healthcare Management Forum 29 (1): 4-7. https://doi.org/10.1177/0840470415614842.

Lambert, N, Y N Chen, Y C Cheng, C M Li, G Y Chen, and F Nori. 2013. "Quantum Biology." Nature Physics 9 (10): 18.

Lazerowitz, M. 1970. “A Note on Metaphylosophy.” Metaphilosophy 1 (1): 91.

Levine, J. 1983. "Materialism and Qualia: The Explanatory Gap.” Pacific Philosophical Quarterly 64: 354-61.

Linde, Klaus, Gianni Allais, Benno Brinkhaus, Yutong Fei, Michael Mehring, Emily A. Vertosick, Andrew Vickers, and Adrian R. White. 2016. "Acupuncture for the Prevention of Episodic Migraine.” Cochrane Database of Systematic Reviews. John Wiley and Sons Ltd. https://doi.org/10.1002/14651858.CD001218.pub3.

Linde, Klaus, Gianni Allais, Benno Brinkhaus, Eric Manheimer, Andrew Vickers, and Adrian R White. 2009. "Acupuncture for Migraine Prophylaxis.” In Cochrane Database of Systematic Reviews, edited by Klaus Linde. Chichester, UK: John Wiley \& Sons, Ltd. https://doi.org/10.1002/14651858.CD001218.pub2.

Ludwig, A M. 1966. “Altered States of Consciousness.” Arch.Gen.Psychiatry 15 (0003-990X 
(Print)): 225-34.

Ma'ayan, Avi. 2017. “Complex Systems Biology.” Journal of The Royal Society Interface 14 (134): 20170391. https://doi.org/10.1098/rsif.2017.0391.

Mallardo, D. 1949. "L’incubazione Nella Cristianita Medievale Napoletana.” Analectica Bollandiana 67: 465-98.

Marras, A. 2005. "Consciousness and Reduction.” British Journal of Philosophy of Science 56: 335-61.

Martin, F, F Carminati, and G Galli Carminati. 2010. "Quantum Information, Oscillation and the Psyche." Physics of Particles and Nuclei 41 (3): 425-51.

Melkikh, A V, and A Khrennikov. 2015. "Nontrivial Quantum and Quantum-like Effects in Biosystems: Unsolved Questions and Paradoxes." Prog.Biophys.Mol.Biol. 119 (1873-1732 (Electronic)): 137-61.

Merli, P. G., G. F. Missiroli, and G. Pozzi. 1974. "Electron Interferometry with the Elmiskop 101 Electron Microscope.” Journal of Physics E: Scientific Instruments 7 (9): 729-32. https://doi.org/10.1088/0022-3735/7/9/016.

Mettrie, O J La. 1747. Machine Man and Other Writings. Edited by A Thomson. Cambridge, UK: Cambridge University Press, 1996.

Morris, K. 2009. "Does Functional Reduction Need Bridge Laws? A Response to Marras." British Journal of Philosophy of Science 60: 647-57.

Nagel, E. 1961. The Structure of Science. Problems in the Logic of Explanation. New York, NY, USA: Harcourt, Brace \& World.

Neppe, V M, and E R Close. 2015. "The Concept of Relative Non-Locality: Theoretical Implications in Consciousness Research.” Explore.(NY) 11 (1878-7541 (Electronic)): 102-8.

Oursel, P M. 1923. La Philosopie Comparée. Paris, France: Alcan.

Overgaard, S, P Gilbert, and S Burwood. 2013. "Introduction: What Good Is Metaphilosophy?" In An Introduction to Metaphilosophy., 1-10. Cambridge , UK: Cambridge University Press. https://doi.org/https://doi.org/10.1017/CBO9781139018043.

Padmanabhan, Divya. 2017. "From Distress to Disease: A Critique of the Medicalisation of Possession in DSM-5.” Anthropology \& Medicine 24 (3): 261-75. https://doi.org/10.1080/13648470.2017.1389168.

Palmer, Genie, and Arthur Hastings. 2013. "Exploring the Nature of Exceptional Human Experiences: Recognizing, Understanding, and Appreciating EHEs.” The Wiley-Blackwell Handbook of Transpersonal Psychology. Wiley Online Books. https://doi.org/doi:10.1002/9781118591277.ch18.

Penrose, R. 2016. The Emperor's New Mind: Concerning Computers, Minds, and the Laws of Physics. Oxford, UK: Oxford University Press.

Popper, K R, and J C Eccles. 1977. The Self and His Brain. Berlin: Springer-Verlag.

Poznanski, R R, J A Tuszynski, and T E Feinberg. 2017. Biophysics of Consciousness. London, UK: World Scientific Publishing Co. Pte Ltd.

Priest, G. 1998. “What Is so Bad about Contradictions?” J.Philosophy 95 (8): 410-26. 
Raatikainen, P. 2018. “Gödel's Incompleteness Theorems." In The Stanford Encyclopedia of Philosophy, edited by E N Zalta, 1-68. Stanford, CA, USA: University of Stanford, CA, US.

Rebaglia, A. 1996. Critica Della Ragione Metascientifica. Milano: Franco Angeli.

Revonsuo, Antti, Sakari Kallio, and Pilleriin Sikka. 2009. "What Is an Altered State of Consciousness?" Philosophical Psychology 22 (2): 187-204. https://doi.org/10.1080/09515080902802850.

Riel, R van, and R Van Gulick. 2019. "Scientific Reduction.” In Stanford Encyclopedia of Philosophy, 1-78. Stanford, CA, USA: Stanford Encyclopedia of philosophy. https://plato.stanford.edu/archives/spr2019/entries/scientific-reduction/.

Russell, B. 1912. Problems of Philosophy. Oxford, UK: Oxford University Press. 1959. Wisdom of the West. London: Rathbone Books Ltd.

Ryle, G. 1949. The Concept of Mind. London: Hutchinson.

Scarpi, P. 2012. Le Religioni Dei Misteri. Vol. VI. Milano: Mondadori.

Severino, E. 1980. Legge e Caso. MIlano: Adelphi. 2016. The Essence of Nihilism. Brooklin, NY: Verso.

Solms, Mark, and Jaak Panksepp. 2012. "The 'Id' Knows More than the 'Ego' Admits: Neuropsychoanalytic and Primal Consciousness Perspectives on the Interface Between Affective and Cognitive Neuroscience." Brain Sciences 2 (2): 147-75. https://doi.org/10.3390/brainsci2020147.

Stephenson, Craig. 2015. "The Epistemological Significance of Possession Entering the DSM." History of Psychiatry 26 (3): 251-69. https://doi.org/10.1177/0957154X14562748.

Sturm, T. 2012. "Consciousness Regained? Philosophical Arguments for and against Reductive Physicalism.” Dialogues.Clin.Neurosci. 14 (1958-5969 (Electronic)): 55-63.

Tagliagambe, S, F Fracas, and E Facco. 2020. "On the Way of Understanding Consciousness: The Contribution of Jung \& Pauli between Neurosciences, Philosophy and Quantum Physics." In Quantum Psyche II., edited by F Carminati and et al., in press. UK: Independent Publishing Platform, Giugi's Editions.

Tagliagambe, S, and A Maliconico. 2011. Pauli e Jung. Un Confronto Su Materia e Psiche. Torino: Raffaello Cortina.

Tonelli, A. 2009. Sulle Tracce Della Sapienza. Bergamo: Moretti \& Vitali Editori.

Tye, M. 2018. “Qualia.” In Stanford Encyclopedia of Philosophy, edited by E N Zalta, 1-39. Stanford, CA, USA. https://plato.stanford.edu/archives/sum2018/entries/qualia/.

Ustinova, Y. 2009. Caves and the Ancient Greek Mind: Descending Underground in the Search for Ultimate Truth. Oxford, UK: Oxford UNiversity Press.

Vaitl, D, N Birbaumer, J Gruzelier, G A Jamieson, B Kotchoubey, A Kubler, D Lehmann, et al. 2005. "Psychobiology of Altered States of Consciousness." Psychol.Bull. 131 (0033-2909): 98-127.

Riel, R van, and R Van Gulick. 2019. "Scientific Reduction.” In Stanford Encyclopedia of Philosophy, 1-78. Stanford, CA, USA: Stanford Encyclopedia of philosophy. https://plato.stanford.edu/archives/spr2019/entries/scientific-reduction/. 
Salomon, R., M. Lim, C. Pfeiffer, R. Gassert, and O. Blanke. 2013. "Full Body Illusion Is Associated with Widespread Skin Temperature Reduction.” Frontiers in Behavioral Neuroscience 7 (MAY). https://doi.org/10.3389/fnbeh.2013.00065.

Vecchio, L. 2004. Filosofi e Medici. Quaderni Del Parco Archeologico Di Velia, 3. Pozzuoli: Naus Editoria.

Wakefield, J C. 2010. "Misdiagnosing Normality: Psychiatry's Failure to Address the Problem of False Positive Diagnoses of Mental Disorder in a Changing Professional Environment." $J$ Ment.Health 19 (1360-0567 (Electronic)): 337-51.

Walach, H, and H Romer. 2011. "Generalized Entanglement - A Nonreductive Option for a Phenomenologically Dualist and Ontologically Monist View of Consciousness." In Neuroscience, Consciousness and Spirituality., edited by H Walach, S Schmidt, and B J Wayne, 81-96. Dordrecht: Springer.

Wang, Z, T Solloway, R M Shiffrin, and J R Busemeyer. 2014. "Context Effects Produced by Question Orders Reveal Quantum Nature of Human Judgments." Proc.Natl.Acad.Sci.U.S.A 111 (1091-6490 (Electronic)): 9431-36.

Weber, R. 2013. "“How to Compare?' - On the Methodological State of Comparative Philosophy." Philosophy Compass 8 (7): 593-603.

Wilczek. 2010. The Lightness of Being. Mass, Ether, and the Unification of Forces. Edited by Basic Books. New York, NY.

Zeman, A. 2001. “Consciousness.” Brain 124 (0006-8950): 1263-89. 